\title{
Ultrastructural studies on the palatine tonsil of buffalo (Bubalus bubalis)
}

\author{
Ibrahim Alhaji Girgiri,' Pawan Kumar' \\ 'Department of Veterinary Anatomy, College of Veterinary Sciences Lala Lajpat Rai University of Veterinary and Animal Sciences, Hisar, India
}

Disclose and conflicts of interest: none to be declared by all authors

\begin{abstract}
Introduction: the study examined the ultrastructural features of the palatine tonsils of local mixed breed of buffalo (Bubalus bubalis) using scanning and transmission electron-microscopy.

Materials and methods: the tissue samples were collected from 6 heads of buffaloes killed by captive bolt stunning gun. The

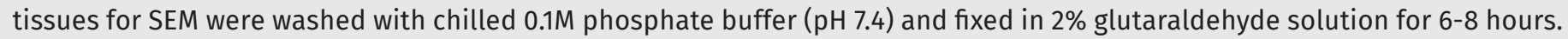
The tissues were dehydrated using ascending grades of alcohol, critical point dried, mounted on stubs and sputter coated with gold, and viewed using a scanning electron-microscope. The tissue samples for TEM were primarily fixed in $2.5 \%$ glutaraldehyde for 6-8 hours and post-fixed in $2 \%$ osmium tetraoxide for 1 hour. The blocks were prepared using epoxy resins and thin sections of $1 \mu$ were stained to select regions of interest. The ultrathin sections were stained and viewed with Technai G2.

Results: the epithelium presented folded mucosa consisting of folds divided by shallow grooves. The surface had a squamous arrangement of cells. The squamous cells at higher magnification presented the microplicae which appeared as if filled with material. A few small ducts opening were irregularly placed throughout the mucosal surface. TEM described structural details of the distinct strata of the surface and reticular epithelia, the cell organelles as well as the lymphocytes migration across the high endothelial venules. The vesiculo-vacuolar organelle was also observed

Conclusion: the study provided detailed ultramicroscopic features of the palatine tonsil which might play a significant role in the induction of immunity against ingested antigens sampled at the mucosal surface.

Keywords: Ultrastructure; Microplicae; Vesiculo-vacuolar organelle; High endothelial venules; Buffaloes.
\end{abstract}

\section{Introduction}

The palatine tonsil a major component of Waldeyer's ring of lymphoid tissue is well positioned along the digestive tract providing defensive barrier against ingested antigens (PERRY and WHITE, 1998). The location plays a key immune inductive role for the tonsil which participates as an effector organ of the local and mucosal adaptive immune responses (BRANDTZAEG, 2003). The tonsil is a specialized structure that contributes to immune functions consist of the reticular crypt epithelium which acts as an inductive site where antigens sampled from the mucosal surface are translocated to underlying lymphoid cells (CHAKER, 2015) and the subepithelial lymphoid compartments consisting of germinal centres in B-cell follicles, surrounded by T-cell rich zones, abundant plasma cells, and a variety of antigen-presenting cells (APCs) comparable to lymph nodes, but not truly encapsulated and lacked afferent lymphatics (BRANDTZAEG et al., 2008). Systemic migration of these lymphoid cells into inductive lymphoid compartments takes place through the high endothelial post-capillary venules (HEVs) (KUMAR and TIMONEY, 2005a; BRANDTZAEG, 2015) regulated by several adhesion molecules and chemokine receptors (KUNKEL and BUTCHER, 2002). The ultrastructural features of palatine tonsils have been earlier described in the horse (KUMAR and TIMONEY, 2005a), camel (ZIDAN and PABST, 2009), and bovine (PALMER et al., 2009). Hitherto, ZIDAN and PABST (2011) described the transmission electron-microscopic features of palatine tonsil in Egyptian buffalo (Bos bubalus). The aim of the present study was to investigate the ultrastructural details of the palatine tonsil of buffalo with an emphasis on distribution of reticular epithelium, lymphoid tissue and associated structures which may be of use to microbiologists to understand and explore the early pathogenesis of diseases like hemorrhagic septicemia in buffaloes.

\section{Materials and Methods}

\section{Scanning electron-microscopy}

Fresh tissues were collected from 6 heads of buffaloes killed by captive bolt stunning gun and fixed in $2 \%$ glutaraldehyde solution for $6-8$ hours at $4^{\circ} \mathrm{C}$, after thorough washing in chilled $0.1 \mathrm{M}$ phosphate buffer $(\mathrm{pH}$ 7.4) stored at $4^{\circ} \mathrm{C}$. The tissues were rewashed twice with $0.1 \mathrm{M}$ phosphate buffer and rest of the procedure was carried out at EM Lab., AIRF, JNU and AIIMS, New Delhi. The tissues were dehydrated using ascending grades of alcohol, critical point dried, mounted on stubs and sputter coated with gold. The tissues were viewed using scanning electron-microscope (Zeiss EVO-40). 


\section{Transmission electron-microscopy}

The fresh tonsillar tissues were washed with $0.1 \mathrm{M}$ phosphate buffer $\left(4^{\circ} \mathrm{C}\right)$ and primarily fixed in $2.5 \%$ glutaraldehyde solution for 6-8 hours followed by post-fixation in $2 \%$ osmium tetraoxide for 1 hour at $4^{\circ} \mathrm{C}$. The blocks were prepared using epoxy resins and thin sections of $1 \mu$ were stained with Toluidine blue to select the most appropriate region of interest of the tissues. The ultrathin sections $(50-70 \mathrm{~nm})$ were taken on copper grids, stained with lead citrate and uranyl acetate. The processed tissues were viewed under transmission electron-microscope (Technai G2) to record areas of interest for observations and photographs.

\section{Results}

Scanning electron-microscopy

The palatine tonsil presented a folded mucosa where a few main longitudinal folds were present and these folds further presented transversely oriented grooves and folds which were of varying shapes and size (Figures $1 \mathrm{~A}, \mathrm{~B})$. Some of the folds were extending throughout the width of these longitudinal folds whereas some other folds reached only up to half of these longitudinal folds. These grooves and folds were like the small narrow crests. The large sized, oval or crescent shaped crypts were distinctly visible (Figures 1 A,C). These crypts were also surrounded by the folded mucosa which presented the transversely oriented smaller folds (Figure $1 \mathrm{C}$ ). The surface of the palatine tonsil presented the continuous sheet of cells which were of irregular shapes and size and were continuous with each other and at places desquamating cells were also observed. The further magnification of these cells presented the microplicae which were of varying patterns and shape but these were appearing as if filled with some material and thus the spaces between the microplicae were drastically reduced (Figures 1 D, 2 A).
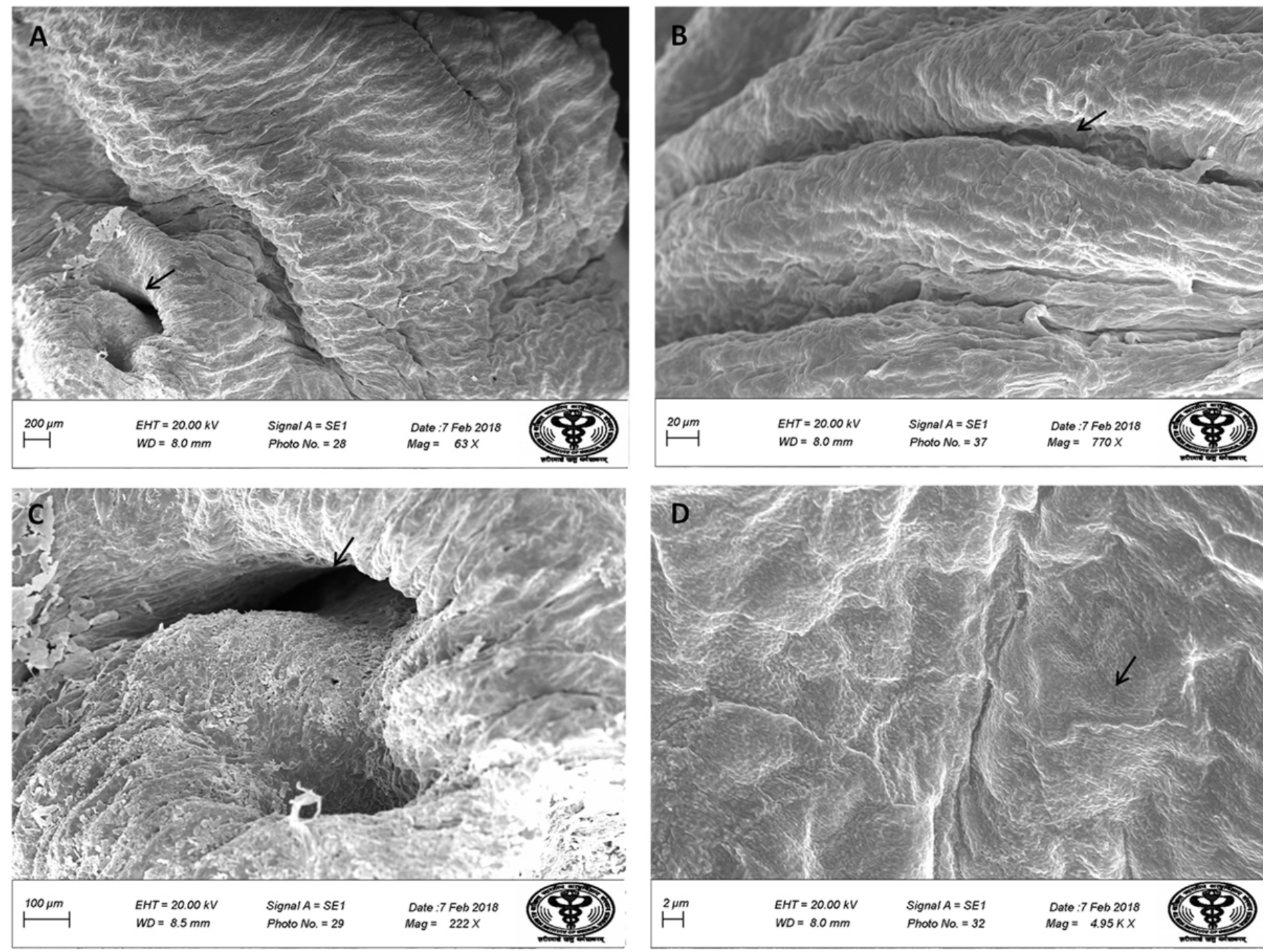

Figure 1. Scanning electron-micrograph of palatine tonsil of buffalo. (A) Folds, and distinctly large sized crypts (arrow). Mag $\times 63$ (Bar 200 $\mu m$ ); (B) Fig.2. Higher

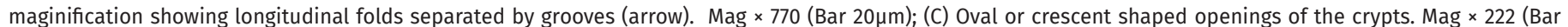
$100 \mu \mathrm{m})$; (D) Arrangement of squamous cells having microplicae (arrow). Mag $\times 4950$ (Bar $2 \mu \mathrm{m})$. 
Small ducts openings observed in between the cells of the surface of the palatine tonsil presented narrow lumen-like structure being obliterated because of the presence of the projection of the cells or secretions of the gland. The cells lining the duct did not present microplicae, rather presented irregular surface having small projections like microvilli. The cut surface of the palatine tonsil presented distinctly visible crypts being lined by a folded group of cells and the surface of these cells were surrounded by very fine droplet of the secretion (Figure $2 \mathrm{~B}$ ). The inner surface presented the microplicae like arrangement which were generally like the colonies of the bacteria (Figure $2 \mathrm{C}$ ). The cut surface also revealed the presence of the lymphoid tissue, showing the presence of lymphocytes and the lymphoid follicles (Figure 2 D). These lymphocytes were also of varying shapes and size and were generally present in an overlapping pattern.

\section{Transmission electron-microscopy}

The palatine tonsil lined by stratified squamous epithelium demonstrated distinct cell layers. The stratum basale was having cuboidal to columnar
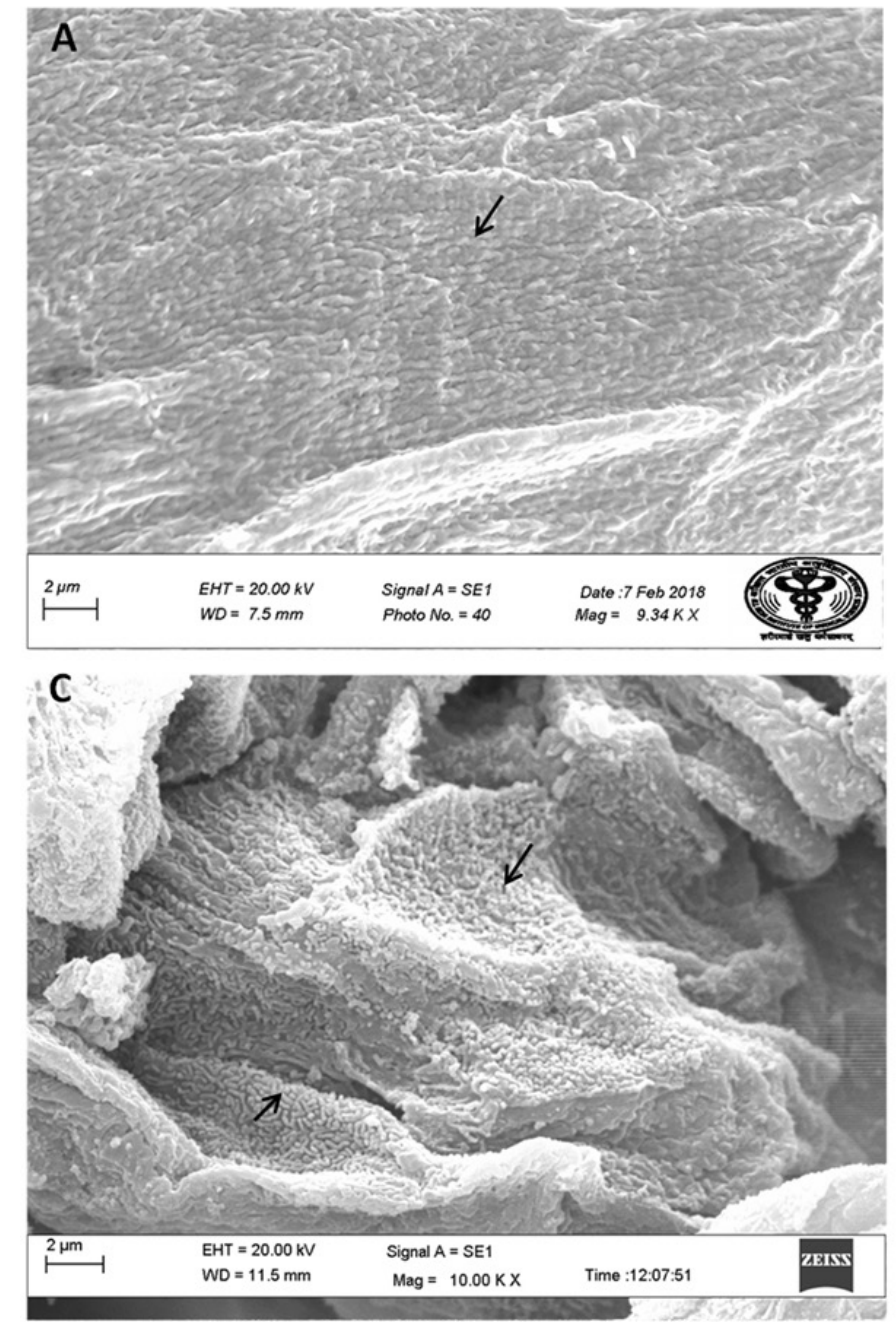

shaped cells and their nuclei were vertically oriented having single nucleolus. The chromatin material was aggregated into smaller clumps towards the nuclear membrane. The electronplasm of these cells was having different cell organelles especially the mitochondria, smooth and rough endoplasmic reticulum, few Golgi bodies and electron-dense granules throughout the nucleoplasm. The adjacent cells presented small interdigitating villi which were attached by desmosomes at different places.

The cells of stratum spinosum presented electronlucent nuclei having irregular surface some which presented nuclear indentations. The electron-dense chromatin material was localized into smaller clumps. The electronplasm presented the different cell organelles and the tonofilaments. The intercellular spaces presented the interdigitating villi which were closely associated with each other (Figure $3 \mathrm{~A}$ ). The vertically oriented nuclei close to the stratum basale became horizontal towards the superficial layers. The cells of the stratum granulosum presented comparatively larger sized nuclei which were also electron-lucent.
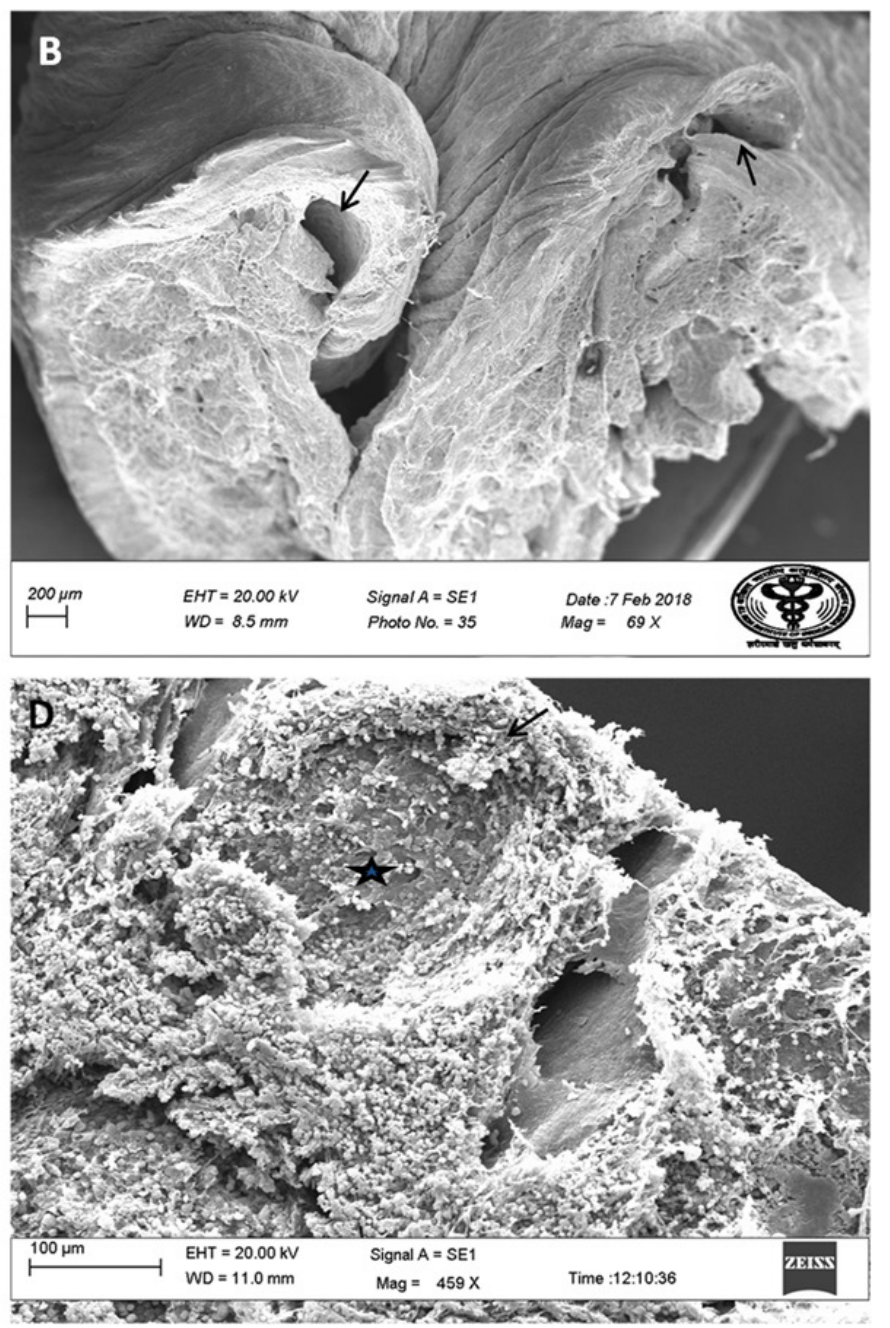

Figure 2. Scanning electron micrograph of palatine tonsil of buffalo. (A) Higher magnification showing microplicae of varying shapes and size (arrow). Mag $\times 9340$ (Bar $2 \mu \mathrm{m})$; (B) Cut surface of the palatine tonsil with distinctly visible crypts (arrow). Mag $\times 69$ (Bar 200 $\mu \mathrm{m}$ ); (C) Inner surface of the crypt presenting the microplicae like bacterial colonies (arrow). Mag $\times 10000($ Bar $2 \mu \mathrm{m})$; (D) Cut surface showing the germinal centre (star), corona (arrow) and parafollicular area. Mag $\times 459($ Bar $100 \mu \mathrm{m})$. 
The cells of the stratum corneum had long processes and were present in the form of serpentine or interlacing arrangement (Figure $3 \mathrm{~B}$ ). Generally their free surfaces presented the undulating appearance. Only few of these cells showed the presence of the nuclei which were smaller and pyknotic in appearance. Majority of the cells were electron-lucent, however a few electron-dense cells were also interposed in between the electron-lucent cells (Figure $3 \mathrm{~B}$ ). The intercellular spaces of these cells also presented the interdigitating villi. In addition to these, a few lymphoid cells especially the lymphocytes were also observed in between the cells at different heights of the epithelium.

The epithelium towards the crypts presented the stratified squamous non-keratinized epithelium having varying number of rows of nuclei of different strata. The stratum basale at places presented vertically oriented nuclei; whereas at some other places presented horizontally placed nuclei which were electron-lucent in appearance. The features of the different cell layers were more or less similar to those of the outer surface epithelium, except that the stratum superficiale had few cell layers and their nuclei were horizontally placed. The stratified squamous non-keratinized epithelium further modified into reticular epithelium because of infiltration of underlying lymphoid cells especially the lymphocytes. The reticular epithelium had indistinct rows of cells and at places it was difficult to discern the epithelial and lymphoid cells. The stratum superficiale was drastically reduced in thickness and its outermost layer presented small microvilli-like structures towards the free surface (Figure $3 \mathrm{C}$ ) which also showed the presence of lymphoid cells especially the lymphocytes and occasionally the granulocytes or macrophages.

The lamina propria was having clusters of lymphocytes which were of varying shapes and size. The majority of the lymphocytes had electron-dense chromatin which was aggregated into smaller clumps. The majority of the nuclei had irregular outer surface. In between the lymphocytes, a few plasma cells were also observed which presented electron-dense chromatin material arranged in the form of spikes of cart wheel (Figure $3 \mathrm{D}$ ) and these cells were having more distribution of the endoplasmic reticulum. In addition, at some places a few macrophages were also
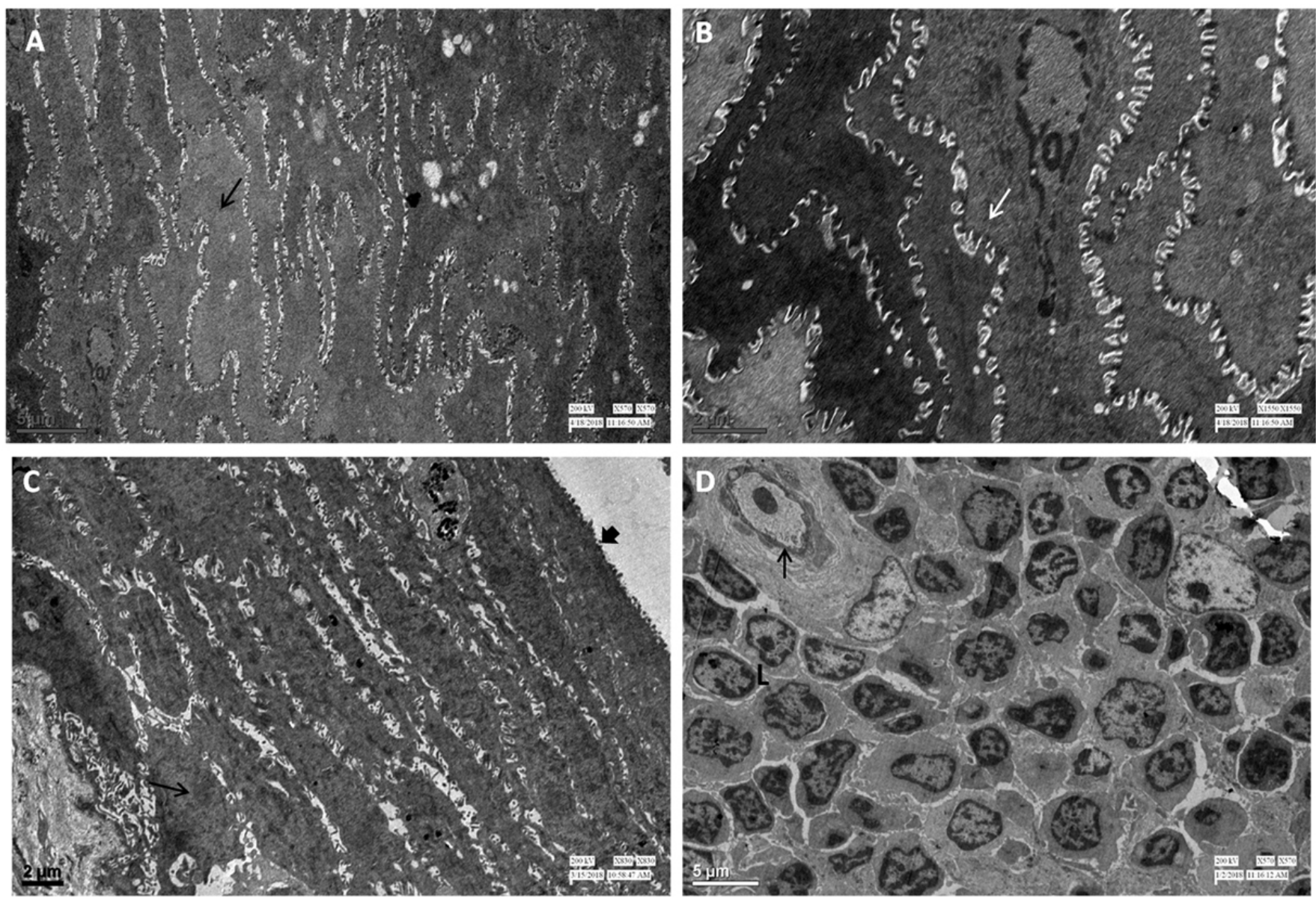

Figure 3. Transmission electron-micrograph of palatine tonsil of buffalo. (A) Electron-lucent cells (arrow) of stratum spinosum of keratinized epithelium. Mag $\times 570$ (Bar $5 \mu \mathrm{m}$ ); (B) Cells of stratum corneum (arrow) with long processes arranged in serpentine or interlacing manner. Mag $\times 1550$ (Bar $2 \mu \mathrm{m})$; (C) Strata basale (arrow),

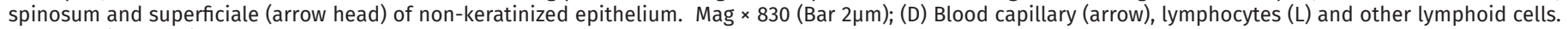
Mag $\times 570($ Bar $5 \mu \mathrm{m})$. 
observed. In between the clusters of the lymphocytes, a few interdigitating cells, reticular cells and fine blood capillaries were also observed. At some places, a few cells having very large sized electron-lucent nuclei were also observed in close proximity to the lymphoid cells. Their nuclei presented very small concentration of electron-dense chromatin.

High endothelial venules (HEV's) were observed towards the periphery of the lymphoid tissue or the interfollicular areas. The HEV's had high cuboidal type of endothelial cells having high cuboidal nuclei which were of irregular shapes (Figures 4 A,B). Generally the basal surfaces of these cells were pointed and narrow as compared to those of simple squamous endothelial cells. The endothelial cells had electron-lucent nuclei having small concentration of electron-dense chromatin material only towards the outer nuclear membrane and these nuclei contained one centric/eccentric nucleolus. The cytoplasm of these cells contained few mitochondria, smooth and rough endoplasmic reticulum, a few Golgi bodies, multivesicular bodies or membrane bound bodies and large number of lysosome-like structures. These cells presented cytoplasmic processes of varying size projecting towards the lumen (Figures 4 C,D). These processes presented electron-dense electronplasm having a few filaments and at places some granules and small vesicles like structures arranged in different patterns called as vesicular vacuolar organelle (VVOs) were observed (Figure $4 \mathrm{D}$ ). The VVO's were observed along with small and large sized vesicles and vacuoles. The VVO's however were oriented in the form of small clusters arranged in different patterns and these were bounded by membranes and were interconnected with each other. In addition, at some places a few multivesicular bodies were also observed (Figures 5 A,B). A few lymphocytes were observed trafficking in the form of inter-endothelial migration or transvascular migration.
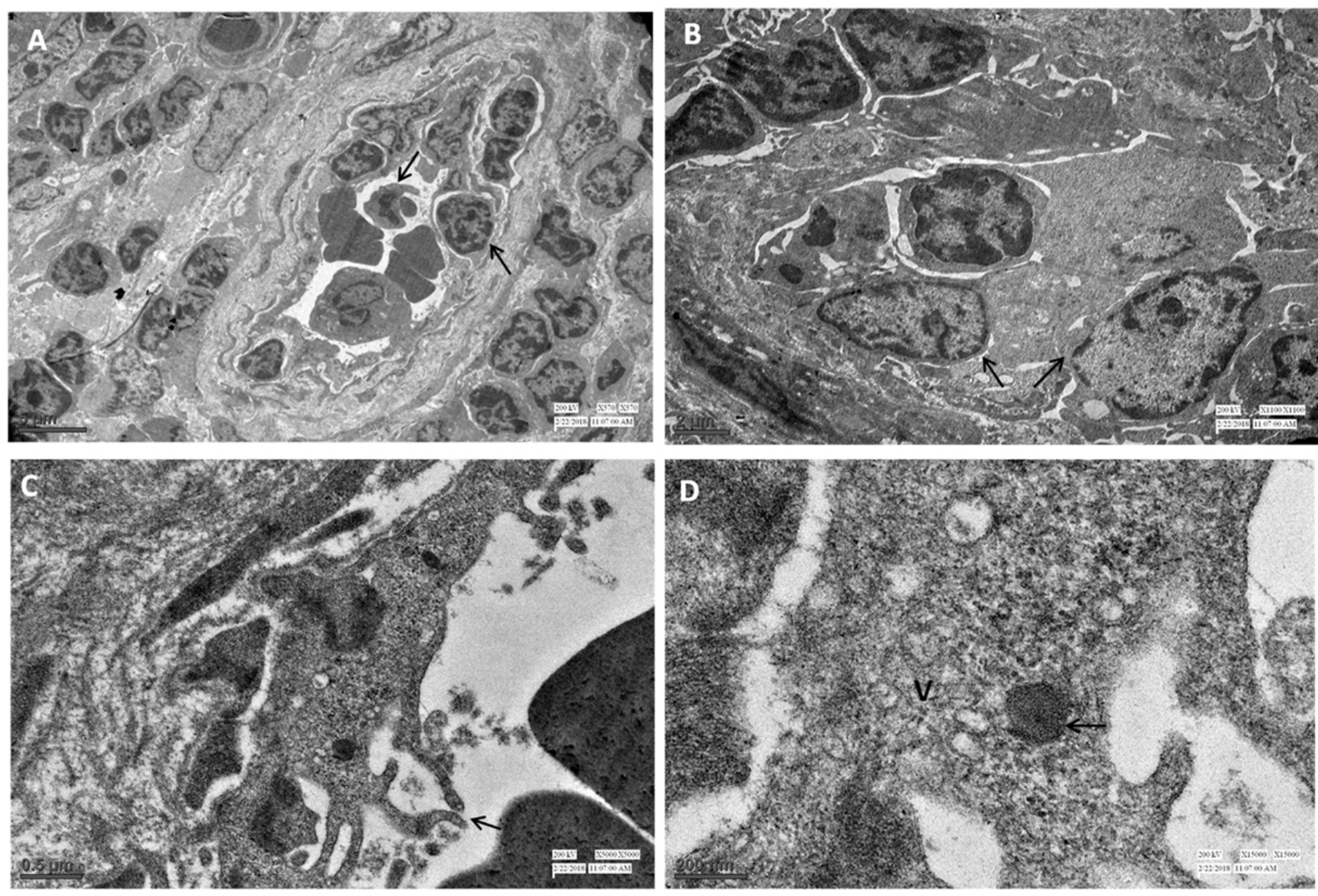

Figure 4. Transmission electron micrograph of palatine tonsil of buffalo. (A) High endothelial venule with lymphocytes (arrow) towards the periphery and within the lumen. Mag $\times 570$ (Bar 5 $\mu \mathrm{m})$; (B) Endothelial cells (arrow) of high endothelial venule along with lymphocyte in the propria-submucosa. Mag $\times 1100$ (Bar $2 \mu \mathrm{m}) ;(\mathrm{C})$ The cytoplasmic processes (arrow) of the endothelial cell projecting towards the lumen. Mag $\times 5000$ (Bar 0.5 $\mu \mathrm{m}$ ); (D) Higher magnification showing vesiculo-vacoular organelle (V) and multivesicular body (arrow). Mag × 15000 (Bar 200nm). 

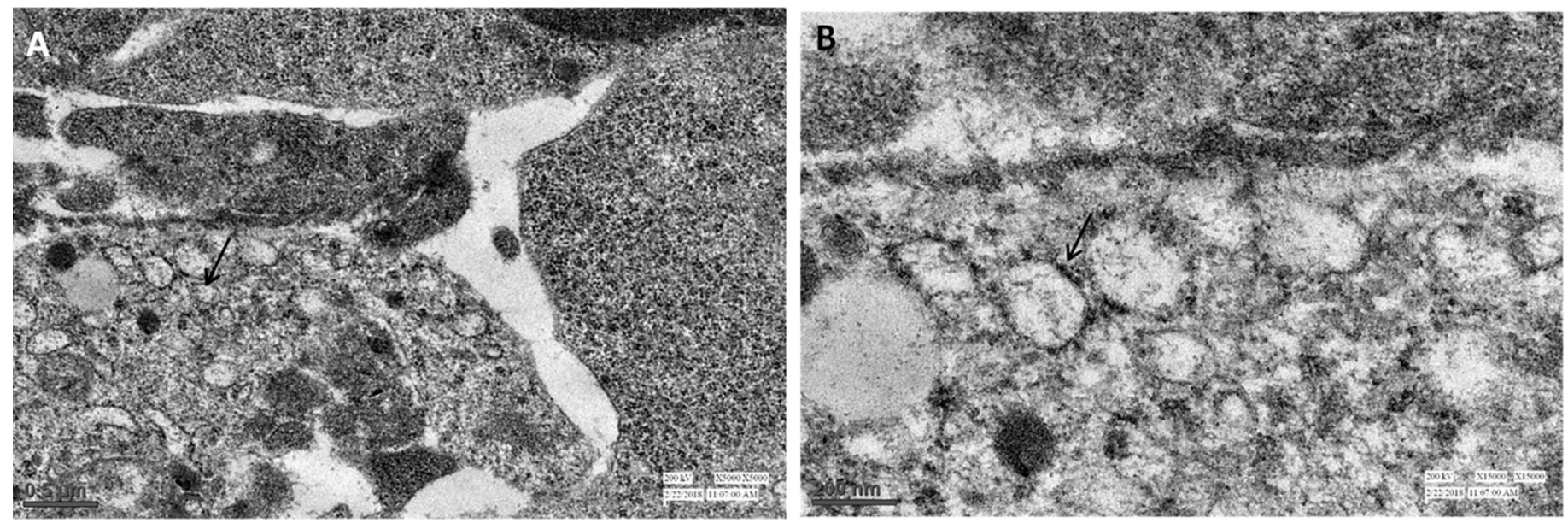

Figure 5. Transmission electron micrograph of palatine tonsil of buffalo. (A) Cytoplasmic processes of the endothelial cells with caveolae (arrow) and vesicles. Mag $\times$

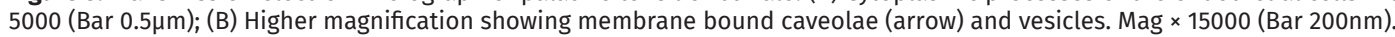

\section{Discussion}

SEM revealed folded mucosa comprised of longitudinal folds which further presented transversely oriented grooves and folds as reported in the sheep (KUMAR et al., 2009), whereas, a large papilla like structure and small elevated area separated from each other by linear folds and depression was observed in the goat (KUMAR et al., 2006). These grooves and folds in this study resembled small narrow crest. In the bovine, the epithelial surface was formed mostly by flat angular squamous cells and intermittently round to oval cells surrounded by closely packed knob-like microvilli (PALMER et al., 2009). Large sized distinctly visible crypts with oval or crescent shape openings were observed as reported in the sheep (KUMAR et al., 2009). In the horse, the crypts were deep, branched and extended almost the entire depth of the tonsil (KUMAR and TIMONEY, 2005b). The crypts contained desquamating epithelial cells, lymphoid cells and degenerating lymphoid cells along with their debris (KUMAR et al., 2009).

Small ducts openings were also observed in between the surface cells. These openings had narrow lumen-like structure being obliterated because of the projection of the cells or secretion of the glands. In the camel, small nodules with irregular luminal surface containing one or two apical openings leading to a crypt and surrounded by circular mucosal ridge was reported (ZIDAN and PABST, 2009). The cut surface in the present study revealed the present of the lymphoid tissue especially lymphocytes and the lymphoid follicles as reported in the horse (KUMAR and TIMONEY, 2005b). These follicles presented small fibroblast-like cells and large cells morphologically consistent with antigen-bearing follicular dendritic cells or macrophage in human palatine tonsil (JOVIC et al., 2015).

The palatine tonsil was lined by stratified squamous epithelium having stratum basale, spinosum, granulosum and corneum. The cell of the stratum basale revealed vertically oriented nuclei with small clumps of electron-dense chromatin material. The mitochondria, smooth and rough endoplasmic reticulum, few Golgi bodies comprised the different organelles. These were more numerous in the horse, in addition to the large numbers of polyribosomes, and tonofilaments (KUMAR and TIMONEY, 2005b). The cells of stratum spinosum presented electronlucent nuclei which had irregular surface and dense chromatin in small clumps as described in the horse (KUMAR and TIMONEY, 2005b). The distribution of the cellular organelles was similar to that of stratum basale. In the horse, Langerhans cells interspersed between these cells contained large number of phagosomes, Golgi bodies, mitochondria, vacuoles, endoplasmic reticulum and characteristic dumbbell-shaped Birbeck granules which were formed by langerin, a C-type lectin responsible for the uptake of mannosylated bacterial antigens (KUMAR et al., 2005b; VALLADEAU et al., 2000). These cells were not observed during present study. However, these cells along with monocytes and macrophages were involved in phagocytosis, processing and presentation of foreign antigens (YAMAMOTO et al., 1988). The intercellular spaces presented the interdigitating villi which were closely associated with each other. The ultrastructural features of the cells of stratum granulosum were almost similar to those of stratum spinosum except the concentration of filaments which was reduced and the granules were comparatively more in number. The cells of the stratum corneum possessed long processes and were arranged in zigzag or serpentine manner. Their nuclei were few and pyknotic in appearance.

The stratum basale of the non-keratinized epithelium had vertical or horizontally placed electronlucent nuclei. The electron-dense basal cells were cuboidal or cylindrical in shape with large oval nuclei in human, (PERRY, 1994). In ovine, it was observed that the thickness of the epithelium varied from one to more than 10 cell layers (CASTELEYN et al., 2010). The features of rest of the cell layers were comparable 
to those of the outer surface epithelium. The cells on the outermost layer of stratum superficiale presented small microvilli-like arrangement towards the free surface as reported in human (PERRY, 1994), horse (KUMAR and TIMONEY, 2005b) and ovine (CASTELEYN et al., 2010). The stratified squamous non-keratinized epithelium was modified into reticular epithelium which was having further reduced number of rows of different strata. The main characteristic feature was an irregular arrangement of epithelial cells and their close association with infiltrated lymphoid cells. These were often associated with lymphoid cells especially the lymphocytes and occasionally the granulocytes or macrophages. These may be the precursors of M-cells capable of pinocytosis in the lympho-epithelial tissue (OLAH et al., 1988). In the ovine, some penetrating electron-dense cytoplasmic processes from cells located underneath the covering squamous were additionally observed with no obvious organelles (CASTELEYN et al., 2010). The outer most layer of stratum superficiale was intact and its cells presented small microvilli like arrangement.

The lymphoid parenchyma was comprised majority of lymphocytes in addition to few plasma cells, macrophages, interdigitating cells, reticular cells and fine blood capillaries as observed in the horse (KUMAR and TIMONEY, 2005b), camel (ZIDAN and PABST, 2009) and the Egyptian buffalo (ZIDAN and PABST, 2011). Electron-dense deposits on the plasma membranes of some follicular dendritic cells were identified as immune complexes (VELINOVA et al., 2001).

The periphery of lymphoid tissue as well as the interfollicular regions presented the specialized high endothelial venules as observed in the horse (KUMAR and TIMONEY, 2005b), camel (ZIDAN and PABST, 2009) and the Egyptian buffalo (ZIDAN and PABST, 2011). The endothelial cells of the specialized vessels presented the cytoplasmic processes of varying size projecting towards the lumen. These processes presented electron-dense electronplasm which possessed caveolae and small vesicles distributed either isolated or in small clusters, a few multivesicular bodies, and the VVO's as described earlier in the horse (KUMAR and TIMONEY, 2005b), and the camel (ZIDAN and PABST, 2009). A few lymphocytes were observed trafficking through the endothelial wall either in the form of inter-endothelial or transvascular migration. High endothelial venules were the most important structures in the tonsillar interfollicular regions participating in the continuous migration of lymphocytes from the blood to the tonsillar lymphoid tissue (HAFEEZ et al., 2008). A few peripheral weaker layers of the basal lamina surrounding the HEV provided circumferential compartments for migrating lymphocytes (SUNAMI-KATAOKA et al., 2001). Expression of vascular adhesion molecules such as VCAM-1, VAP-1, P-selectin, L-selectin played a key role in adhesion of lymphocytes to endothelial cells of HEVs and their migration from the blood into the tonsil (PERRY and WHITE, 1998).

\section{Conclusion}

The SEM revealed mucosal folds of varying shapes, the surface of which presented the squamous arrangement of cells. The higher magnification revealed the microplicae which appeared as filled structures. Distinct crypts and a few glandular ducts openings were observed irregularly on the mucosal surface whereas; the TEM demonstrated the different cell organelles of the distinct strata of the surface epithelium, the cellular profiles of propria submucosa as well lymphocyte migration across the high endothelial venules via the intra-endothelial and transendothelial route.

\section{Acknowledgements:}

The Indian Council for Cultural Relation, ICCR, is kindly acknowledged for international Ph.D. fellowship to Dr. Ibrahim Alhaji Girgiri. The facilities provided by EM Lab., AIIMS, New Delhi and AIRF, JNU, New Delhi are sincerely acknowledged.

\section{References}

1. BRANDTZAEG, P. Immunology of tonsils and adenoids: everything the ENT surgeon needs to know. International Journal of Pediatric Otorhinolaryngology, 2003, vol. 67S1, p. 69-76.

2. BRANDTZAEG, P., KIYONO, H., PABST, R. and RUSSELL, M.W. Terminology: nomenclature of mucosa-associated lymphoid tissue. Mucosal Immunology, 2008, vol. 1, p. 31-37.

3. BRANDTZAEG, P. The mucosal B cell system. Mucosal Immunology, 2015, vol. 2, p. 623-681.

4. CASTELEYN, C., CORNELISSEN, M., SIMOENS, P. and VAN DEN BROECK, W. Ultramicroscopic examination of the ovine tonsillar epithelia. Anatomical Record, 2010, vol. 293, p. 879-889.

5. CHAKER, A. Anatomy and microanatomy of tonsils. Encyclopedia of Immunobiology, 2015, vol.3, p. 420-426.

6. HAFEEZ, A., KHAN, M.Y. and MINHAS, LA. The relative distribution of high endothelial venules in the subepithelial lymphoid compartments of human palatine tonsil. Annals of Pakistan Institute of Medical Science, 2008, vol. 4(4), p. 223-226.

7. JOVIĆ, M., AVRAMOVIĆ, V., VLAHOVIĆ, P., SAVIĆ, V., VELIČKOV, A. and PETROVIĆ, V. Ultrastructure of the human palatine tonsil and its functional significance. Romanian Journal of Morphology and Embryology, 2015, vol. 56(2), p. 371-377.

8. KUMAR, P., KUMAR, P. and KUMAR, S. Light and scanning electron microscopic studies on the palatine tonsil of the goat. Indian Journal of Animal Sciences, 2006, vol. 76(12), p. 1004-1006.

9. KUMAR, P., SINGH G. and NAGPAL, S.K. Scanning and transmission electron microscopic studies on the palatine tonsil of sheep. Haryana Veterinarian, 2009, vol.48, p. 33-38.

10. KUMAR, P. and TIMONEY, J.F. Histology and ultrastructure of the equine lingual tonsil. I. Crypt epithelium and associated structures. Anatomia Histologia Embryologia, 2005a, vol. 34, p. 27-33. 
11. KUMAR, P. and TIMONEY, J.F. Immunohistochemistry and ultrastructure of the equine palatine tonsil. Anatomia Histologia Embryologia, 2005b, vol. 34, p. 192-198.

12. KUNKEL, E.J. and BUTCHER, E.C. Chemokines and the tissuespecific migration of lymphocytes. Immunity, 2002, vol. 16, p. 1-4.

13. OLAH, I., TAKACS, L. and TORO, I. Formation of lymphoepithelial tissue in the sheep's palatine tonsil. Acta Otolaryngology, (Stockh) 1988, vol. 454, p. 7-17.

14. PALMER, M.V., THACKER, T.C. and WATERS, W.R. Histology, immunohistochemistry and ultrastructure of the bovine palatine tonsil with special emphasis on reticular epithelium. Veterinary Immunology and Immunopathology, 2009, vol. 127, p. 277-285.

15. PERRY, M.E. The specialized structure of crypt epithelium in the human palatine tonsil and its functional significance. Journal of Anatomy, 1994, vol. 185, p. 111-127.

16. PERRY, M. and WHYTE, A. Immunology of the tonsils. Immunology Today, 1998, vol. 19, p. 414-421.

17. SUNAMI-KATAOKA, Y., AKAGI, H., NISHIZAKI, K., TAGUCHI, T., MURAKAMI, T. and OHTSUKA, A. Chondroitin sulfate proteoglycan at the basal lamina beneath high endothelial cells in human palatine tonsils: A light and electron microscopic study using the cationic colloidal iron method. Archives of Histology and Cytology, 2001, vol. 64, p. 535-543.

18. VALLADEAU, J., RAVEL, O. and DEZUTTER-DAMBUYANT, C. Langerin, a novel C-type lectin specific to Langerhans cell, is an endocytic receptor that induces the formation of Birbeck granules. Immunity, 2000, vol. 12, p. 71-81.

19. VELINOVA, M., THIELEN, C., MELOT, F., DONGA, J., EICHER, S., HEINEN, E. and ANTOIN, N. New histochemical and ultrastructural observations on normal bovine tonsils. Veterinary Record, 2001, vol. 149, p. 613-617.

20. YAMAMOTO, Y., OKATO, S., TAKAHASHI, H., TAKEDA, K. and MAGARI, S. Distribution and morphology of macrophages in palatine tonsils. Acta Otolaryngology, Suppl. 1988, vol. 45, p. 83-95.

21. ZIDAN, M. and PABST, R. The microanatomy of the palatine tonsils of the one-humped camel (Camelus dromedarius). Anatomical Record, 2009, vol. 292, p. 1129-1197.

22. ZIDAN, M. and PABST, R. The microanatomy of the palatine tonsils of the buffalo (Bos bubalus). Veterinary Immunology and Immunopathology, 2011, vol. 139, p. 83-89.
Received: August 8, 2019

Accepted: January 3, 2020
Corresponding author

Pawan Kumar

pkumar@luvas.edu.in 